\title{
Psicologia e regimes de verdade nas práticas de promoção da saúde
}

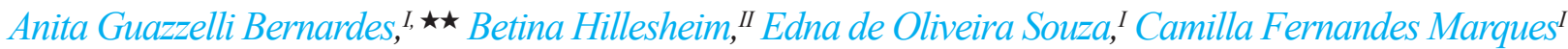

${ }^{I}$ Universidade Católica Dom Bosco, Campo Grande, MS, Brasil

II Universidade de Santa Cruz do Sul, Santa Cruz do Sul, RS, Brasil

Resumo

O presente estudo focaliza as ações em promoção de saúde produzidas pela Psicologia na rede de saúde descritas em periódicos científicos a partir da implantação e implementação da Política Nacional de Promoção de Saúde. Os periódicos, assim como a Declaração de Alma-Ata, a Carta de Ottawa e a própria Portaria 687/06, compõem os materiais analisados. As ferramentas conceituais da análise amparam-se nas discussões foucaultianas sobre regimes de verdade e políticas de subjetivação. A discussão considera as práticas psicológicas, na atenção básica, como um campo de experiência que constitui a figura grupal, forjada pelo testemunho e pela aprendizagem como tecnologias de governo de si e do outro.

Palavras-chave: Psicologia; regimes de verdade; promoção da saúde; politicas de subjetivação.

\section{Psychology and regimes of truth in health promotion practices}

\begin{abstract}
The present study focuses on the actions for health promotion produced by Psychology in the health care network as described in scientific journals for both the implantation and implementation of the National Health Promotion Policy. The journals, as well as the Declaration of Alma-Ata, the Ottawa Charter and the Resolution 687/06 itself, constitute the analyzed materials. The conceptual tools of this analysis are grounded on Foucauldian discussions about the regimes of truth and subjectivation policies. The discussions consider the psychological practices in primary health care as a field of experience that constitutes the group figure shaped through testimony and learning as technologies of government of both the self and the other.
\end{abstract}

Keywords: health promotion; psychological practices; subjectivation policies; technologies of government

Este artigo tem o objetivo de analisar práticas de promoção de saúde produzidas pela Psicologia. Essa discussão faz parte de um projeto de pesquisa que vem se desenvolvendo desde 2009 e tem como foco as práticas psicológicas em articulação com o campo das políticas públicas. O presente estudo enfoca as ações em promoção de saúde produzidas pela Psicologia na rede de saúde descritas em periódicos científicos a partir de 2006, quando a Portaria 687/06 (BRASIL, 2006) organiza diretrizes e ações para a implementação da Política Nacional de Promoção de Saúde.

A pesquisa foi realizada na base de dados BVS-PSI e utilizou como descritor a promoção de saúde. A partir desse primeiro levantamento, que resultou num total de 78 artigos, foram destacados 30. Estes 30 artigos foram selecionados em razão de apresentarem relatos de experiências em promoção de saúde pela Psicologia na atenção básica. Deste modo, não se elegeram textos que discutiam a Promoção de Saúde e sim apenas aqueles que indicavam o modo como as práticas psicológicas se caracterizavam como práticas de Promoção de Saúde. $\mathrm{Na}$ etapa seguinte, voltou-se o olhar para aqueles artigos que apresentavam relatos de experiência a partir de práticas que circunscrevem um campo de experiência grupal, ou seja, práticas que se organizavam por intervenções em grupos, sendo então o material reduzido para 23 artigos. Assim, o presente texto discute esses 23 artigos, bem

\footnotetext{
^Financiamento: Conselho Nacional de Desenvolvimento Científico e Tecnológico (CNPq) e Universidade Católica Dom Bosco (UCDB)

$\star \star$ Endereço para correspondência: Universidade Católica Dom Bosco, Mestrado em Psicologia. Av. Tamandaré, 6000 - Jardim Seminário. CEP: 79117900 Campo Grande, MS - Brasil. CEP: anitabernardes@ig.com.br, betinah@unise. br, universoterra577@yahoo.com.br, camilla.fmt@hotmail.com
}

como a Declaração de Alma-Ata (URSS, 1978) e a Carta de Ottawa (CANADÁ, 1986), além da própria Portaria 687/06 (BRASIL, 2006).

O presente texto sistematiza a discussão em três momentos. Primeiro, discute-se a objetivação dos discursos sobre a promoção de saúde como um regime de verdades no campo das políticas de saúde e da Psicologia. Após, mediante a análise dos dados provenientes dos periódicos científicos e documentos supracitados, buscase compreender a aclimatação da promoção da saúde pelas práticas psicológicas, problematizando-se as formas de saber possíveis e as políticas de subjetivação que se produzem a partir das mesmas. Para finalizar, mediante as noções de testemunho e aprendizagem como tecnologias de si e do outro, argumenta-se como as práticas psicológicas configuram, na atenção básica, um campo de experiência grupal.

\section{Regimes de verdade e a Política de Promoção da Saúde}

A promoção de saúde aparece no campo da saúde a partir da década de 1970, quando um conjunto heterogêneo de práticas sociais nacionais e internacionais passa a colocar em análise indicadores de saúde, condições de vida e tecnologias sociossanitárias (BUSS, 2003). Isso faz com que a promoção de saúde apresente uma problemática para o campo da saúde, na medida em que articula uma nova racionalidade, na qual a saúde passa a ser disposta ao lado de condições de vida, renda, trabalho, lazer e educação, e não exclusivamente da doença e do organismo. Conforme descreve Buss (2003, p. 16) sobre o conceito de promoção de saúde,

[...] este termo está associado inicialmente a um conjunto de valores: vida, saúde, solidariedade, eqüidade, democracia, 
cidadania, desenvolvimento, participação e parceria, entre outros. Refere-se também a uma combinação de estratégias: ações do Estado (políticas públicas saudáveis), da comunidade (reforço da ação comunitária), de indivíduos (desenvolvimento de habilidades sociais), do sistema de saúde (reorientação do sistema de saúde) e de parcerias intersetoriais.

De acordo com Foucault (2010a, p. 67), regimes de verdade implicam naquilo "que constrange os indivíduos a um certo número de atos de verdade", estabelecendo para tais atos determinadas condições e efeitos específicos. Desse modo, a partir da compreensão de que a Política de Promoção de Saúde constituise como regime de verdades para a reflexão sobre os modos de aclimatação pelas práticas psicológicas da promoção da saúde, considera-se a promoção da saúde como um regime de verdades na medida em que formará séries, representações, conjunto de valores que, por meio de procedimentos/comportamentos, manifesta o verdadeiro: a promoção de saúde é composta por um conjunto de valores e de estratégias (BUSS, 2003). Esses valores e estratégias produzem arranjos coletivos, ou seja, são regras de um jogo que fabricam, mediante a produção de verdades, certas modalidades de relação dos sujeitos consigo mesmos, criando formas de subjetivação e domínios de objetos.

A promoção de saúde, ao tornar-se parte de certo número de atos de verdade - meios necessários para melhorar a saúde e o autogoverno de uma comunidade -, será ela mesma uma tecnologia de subjetivação no campo da saúde. A resposta da promoção de saúde em relação às condições de vida é, tomando palavras de Deleuze (2008, p. 11), “um processo, ou seja, uma passagem de Vida, que atravessa o vivível e o vivido". A problemática reside no modo como uma passagem de vida que se furtaria a qualquer formalização, acaba por tornar-se um regime de verdades, uma política de subjetivação. Esse procedimento de captura daquilo que escapa torna-se possível quando se consideram a circulação e mobilização dessa produção de verdades em termos de formas de aclimatação. A circulação e a mobilização não são consideradas como estratégias de unificação, mas como movimentos que constituem regiões de aproximação entre distintos elementos, por exemplo, a promoção de saúde da ausência de doenças especificamente.

Deste modo, por regimes de verdade se compreende uma forma de organização daquilo que se diz a partir de um conjunto de regras que apoiam o que é da ordem do verdadeiro. Essas regras são modalidades que definem o dizer como um enunciado da verdade, ou seja, estabelecem os elementos que devem ser articulados para que um enunciado seja tomado como verdadeiro. Não se trata, então, de quem ou o lugar de enunciação da verdade, mas do modo como ao dizer afirma-se um conjunto de relações que sustentam a verdade do que é dito. A atualização dos regimes de verdade se dá através de exercícios de poder, de formas de governo que

Fractal, Rev. Psicol., v. 28 - n. 1, p. 2-8, 2016 permitem que um enunciado saia de uma região do que se consideraria como designação de objetos, para uma dimensão pragmática, de produção dos próprios objetos.

No que se refere à noção da promoção de saúde, aponta-se que a mesma emerge como um regime de verdade na medida em que se apoia tanto em um conjunto heterogêneo de regras que modificam as práticas em saúde, tais como direito, cidadania, equidades sociais, quanto por tecnologias de cuidado que as articulam no cotidiano como promotoras de saúde, tais como as diretrizes de ações das práticas em saúde. Nesse sentido, a primeira Conferência Internacional de Promoção de Saúde (CANADÁ, 1986) constitui-se como uma resposta ao que se organizara na Declaração de Alma-Ata (URSS, 1978). Esta pressupôs um direcionamento das ações de saúde para a atenção primária, com o objetivo de alcançar "Saúde para todos no ano 2000” (URSS, 1978). Isso significava não apenas investir no desenvolvimento técnico-científico, mas considerar que a saúde reflete as condições econômicas, socioculturais e políticas de um país; portanto, torna-se necessário descentralizar do setor da saúde as ações que devem ser construídas como forma de se alcançarem melhores condições de saúde.

Portanto, os regimes de verdade se tornam formas de produção de verdades a partir de relações de poder que os atualizam. Nestes jogos entre verdade e poder se produzem subjetividades. A produção de subjetividade refere-se às modalidades de relação que os sujeitos estabelecem consigo, com o outro e com o mundo que habitam. São formas de condução da própria conduta no que diz respeito ao modo como nos reconhecemos, como nos percebemos, como vivemos.

Esse regime de verdades acaba por acentuar um campo de experiências no qual a saúde passa a ser objetivada não só como ausência de doença, e sim como vida, cidadania, democracia, participação. A promoção de saúde na Carta de Ottawa surge como um vetor de verdade que faz surgir o que Foucault (2009) denomina como novos modos de subjetivação, novos objetos e domínios de saber. A emergência da promoção de saúde se dá não em razão de uma questão individual, mas, sobretudo, das conexões das experiências de saúde-enfermidade com o plano da Política, seja ela conformada por redes econômicas, jurídicas, culturais, estéticas ou cognitivas. A promoção de saúde, nesse primeiro plano, assume contornos de cidadania a partir de estratégias coletivas, da intensificação das comunidades nos processos de produção de saúde, ou seja, migra de um plano que encerra os processos de saúde-doença na relação medicina-indivíduo para um plano de potência dos coletivos.

Entretanto, é importante marcar que se trata de uma relação agonística, na qual o que se coloca em jogo é certo perspectivismo, um caráter polêmico e estratégico da produção de verdades - indivíduo e coletivos. Em razão de a verdade não ser considerada aqui como da ordem de uma metafísica, e sim efeito de um conjunto múltiplo de relações de força, de lutas por imposição de valores, a promoção de saúde, ao mesmo tempo em que é considerada em sua emergência como uma modalidade 
que romperia com uma perspectiva biomédica, também se torna um regime de verdades. Ferreira Neto et al. (2009) apontam esse caráter polêmico da promoção de saúde ao considerarem que ela se conforma por um plano de bifurcação. Esse plano de bifurcação encaminha a Política tanto para ações de transformação e equidade social quanto para ações de vigilância e regulação neoliberais.

No Brasil, foi lançada, em 2006, a Portaria 687/06, com o intuito de organizar diretrizes e ações para a implementação da Política Nacional de Promoção de Saúde Como portaria, a Política Nacional de Promoção de Saúde constitui um conjunto organizado de elementos que se justapõem - saúde, doença, política, economia, cultura, uma estratégia que atribui funções e relações, redes de significação. Em sua apresentação, a portaria afirma que há "um grande esforço na construção de um modelo de atenção à saúde que priorize ações de melhoria da qualidade de vida dos sujeitos e coletivos" (BRASIL, 2006, p. 5). Além disso, o texto da portaria destaca o compromisso com o Pacto pela Vida, propondo uma política transversal, integrada e intersetorial, a partir da formação de redes entre setores governamentais, setores privados e não-governamentais e a própria sociedade, os quais são tidos como corresponsáveis no que se refere à qualidade de vida da população e o cuidado com a saúde.

Pode-se entender que tal conformação torna essa Política uma forma de governo de acordo com certos valores e estratégias; entretanto, a própria porosidade da Política, ao aproximar-se das necessidades sociais que se fazem presentes no campo da saúde, articula novas modalidades de experiência. Nessa perspectiva, conforme o documento

Tradicionalmente, os modos de viver têm sido abordados numa perspectiva individualizante e fragmentária, e colocam os sujeitos e as comunidades como os responsáveis únicos pelas várias mudanças/arranjos ocorridos no processo saúde-adoecimento ao longo da vida. Contudo, na perspectiva ampliada de saúde, como definida no âmbito do movimento da Reforma Sanitária brasileira, do SUS e das Cartas de Promoção da Saúde, os modos de viver não se referem apenas ao exercício da vontade e/ ou liberdade individual e comunitária. Ao contrário, os modos como sujeitos e coletividades elegem determinadas opções de viver como desejáveis, organizam suas escolhas e criam novas possibilidades para satisfazer suas necessidades, desejos e interesses pertencentes à ordem coletiva, uma vez que seu processo de construção se dá no contexto da própria vida (BRASIL, 2006, p. 10-11).

Assim, não se trata de pensar a promoção em saúde como um conjunto fechado, intransponível, na medida em que a mesma se faz no cotidiano, sendo que a vida se inventa permanentemente. É justamente nessa capacidade de produção de vida e de verdades que as práticas psicológicas, na esteira dos regimes de verdade da saúde, entram em uma zona de aproximação com certas modalidades de ação e produção de verdades. A interrogação sobre as práticas psicológicas a partir da aclimatação da promoção de saúde orienta o olhar para essa articulação entre regimes de verdade, relações de poder e políticas de subjetivação.

\section{Aclimatar a promoção de saúde}

Para fins de análise, os artigos selecionados foram organizados no que se refere à caracterização do que eram consideradas práticas de promoção de saúde e os elementos que as fundamentavam, tais como as concepções de saúde/doença e referências às políticas públicas. No que diz respeito ao campo de experiência grupal, considerou-se que as práticas psicológicas se sustentavam principalmente em duas noções: o testemunho e a aprendizagem. Além disso, a promoção de saúde se apresenta nas práticas psicológicas a partir de uma ideia de autoevidência. A problematização se apoiou em autores como Michel Foucault e Gilles Deleuze, especialmente nos conceitos de poder, verdade e políticas de subjetivação. Destaca-se ainda que a análise não objetivou realizar uma hermenêutica das práticas psicológicas, mas, sim, discutir os efeitos daquilo que produzem, ou seja, como as práticas psicológicas produzem regimes de verdade e formas de subjetivação. Além disso, o estudo não parte propriamente de uma periodização - as práticas psicológicas produzidas a partir da Política Nacional de Promoção de Saúde -, mas de um problema que "acontecimentaliza" (FOUCAULT, 2003, p. 339): a aclimatação da promoção de saúde no campo das práticas psicológicas. Considerar a promoção de saúde como uma aclimatação no campo da Psicologia significa pensar sobre os modos como as práticas sociais produzem domínios de saber que não fazem aparecer apenas objetos ou técnicas, mas também produzem formas de subjetivação.

Os periódicos analisados aparecem no texto em itálico, sem identificação dos autores, na medida em que, seguindo os rastros de Foucault (2009), o que interessa para este estudo não são os autores, mas o funcionamento dos enunciados em termos de políticas de subjetivação. Esses textos também não apresentam o número da página das citações, visto que são enunciações que se repetem ao longo do texto ou em diversos textos, bem como a condensação de diferentes passagens dos textos. Sendo assim, os textos serão referenciados por número, estas numerações estão dispostas de acordo com a ordem em que os textos foram encontrados e analisados na pesquisa. Ou seja, a sequência cardinal de organização dos textos indicará ausência de determinados números, em função de que estes textos não foram utilizados para a análise deste artigo. Conforme quadros a seguir: 
Quadro 1:

\begin{tabular}{|c|c|}
\hline Periódicos & Número \\
\hline $\begin{array}{l}\text { SANTOS, A. de O.; NECHIO, D. E. G. A paixäo de fazer: saúde metal e } \\
\text { dispositivo grupal. Fractal: Revista de Psicologia, v. } 22 \text {, n. 1, p. } 127-140 \text {, } \\
\text { jan/abr. } 2010 \text {. }\end{array}$ & 01 \\
\hline $\begin{array}{l}\text { MORAES, A. B. A.; ROLIM, G. S.; COSTA Jr., A. L. O processo de adesäo } \\
\text { numa perspectiva analitico comportamental Rev. Bras. Ter. Comport. Cogn } \\
\text { Säo Paulo, v. } I I, \text { n. } 2 \text {, p. } 329-345 \text {, dez. } 2009 \text {. }\end{array}$ & 02 \\
\hline $\begin{array}{l}\text { BRIGAGÁO, J. I. M.; GONÇALVES, R. O ficinas de promoção de saúde: } \\
\text { discutindo os dilemas do cotidiano de um grupo de agentes comunitárias de } \\
\text { saúde. Paideia, v. } 79 \text {, n. } 44 \text {, p. } 387-393 \text {, set./dez. } 2009 \text {. }\end{array}$ & 03 \\
\hline $\begin{array}{l}\text { SILVA, A. R. de O. et al. Enredando lutas cotidianas: dispositivos de saúde } \\
\text { pela cidade. Fractal, Rev. Psicol. [online], v. } 21, \text { n. 3, p. } 507-520,2009\end{array}$ & 04 \\
\hline $\begin{array}{l}\text { SILVA, M. de P.; MURTA, S. G. Treinamento de Habilidades Sociais para } \\
\text { Adolescentes: Uma Experiência no Programa de Atençäo Integral à Família } \\
\text { (PAIF) Psicologia: Reflexão e Crítica, v. 22, n 1, p. 136-143, 2009. }\end{array}$ & 06 \\
\hline $\begin{array}{l}\text { PEDROSA, C. M. A construção de uma ferramenta social para promo ção da } \\
\text { saúde e dos direit os das mulheres. Paideia, v. } 79 \text {, n } 42, \text { p. } 123-129 \text {, jan. /abr. } \\
2009 \text {. }\end{array}$ & 07 \\
\hline $\begin{array}{l}\text { TAHAN-SANTOS, E.; CARD OSO, C. L. Experiências de participantes em } \\
\text { um Grupo de Promo çăo de Saúde na Estratégia Saúde da Familia. Psico, } \\
\text { Porto Alegre, PUCRS, v. } 39, \mathrm{n} 4 \text {, p. } 410-417 \text {, out./dez. } 2008 \text {. }\end{array}$ & 08 \\
\hline $\begin{array}{l}\text { KLEIN, M. M. de S.; GUEDES, C. R. Intervençäo Psicológica a Gestantes: } \\
\text { Contribuiçóes do Grupo de Suporte para a Promoçäo da Saúde. Psicologia: } \\
\text { Ciência Profissăo, v. } 28, \mathrm{n} 4, \text { p. } 862-871,2008 \text {. }\end{array}$ & 10 \\
\hline $\begin{array}{l}\text { GAMA, C. A. P., KODA, M. Y. Psicologia comunitária e programa de saúde } \\
\text { da familia: relato de uma experiência de estágio. Psicologia: Ciência e } \\
\text { Profissäo, [online], v. } 28, \text { n. 2, p. } 418429,2008 \text {. }\end{array}$ & 11 \\
\hline $\begin{array}{l}\text { FRANÇA, A. C. P, VIANA, B. A. Interface Psicologia e Programa Saúde } \\
\text { da Familia - PSF: Reflexões Teóricas. Psicologia: Ciência e Profissão, v. } \\
26, \text { n. 2, p. 246-257, 2006. }\end{array}$ & 13 \\
\hline $\begin{array}{l}\text { ROMAGNOLI, R. C., MORE RA, J. O, NEVES, E. O. O surgimento da } \\
\text { clínica psicológica: da prática curativa aos dispositivos de promoçäo da } \\
\text { saúde. Psicologia: Ciência e Profissão, v. } 27, \text { n. } 4, \text { p. } 608-621,2007 \text {. }\end{array}$ & 14 \\
\hline $\begin{array}{l}\text { ARPINI, D. M; SANTOS, B.R Programa da criança: espaço de promo çăo de } \\
\text { saúde e fortalecimento dos vinculos. Psicol. Argum., Curitiba, v. } 25 \text {, n. } 49 \text {, p. } \\
155-164 \text {, abr./jun. } 2007 \text {. }\end{array}$ & 15 \\
\hline
\end{tabular}

Quadro 2:

\begin{tabular}{|c|c|}
\hline Periódicos & Número \\
\hline $\begin{array}{l}\text { EIDELWEIN, K. A Psicologia em Projet os So ciais de Educaçăo e Trabalho. } \\
\text { Psicologia \& Sociedade, v. } 77, \mathrm{n} 3, \text { p. } 62-66 \text {, set/dez. } 2005 \text {. }\end{array}$ & 16 \\
\hline $\begin{array}{l}\text { BITTENCOURT, R. A. do A.; FONTOURA MATEUS, M. L. } \\
\text { Possibilidades de Atuação do Psicólogo no Programa Saúde da Família: A } \\
\text { Experiência de Bonito-Ms. Psicologia: Ciência e Profissão, v. 26, n. 2, p. } \\
328-343,2006 \text {. }\end{array}$ & 17 \\
\hline $\begin{array}{l}\text { ALVES, R. F.; EULALIO, M. do C.I; BROB EIL, S. A. J. La promoción de } \\
\text { la salud y la prevención de enfermedades como actividades propias de la } \\
\text { labor de los psicólogos. Arquivos Brasileiros de Psicologia, v. } 67, \text { n. } 2, \text { p. } \\
01-12,2009 \text {. }\end{array}$ & 18 \\
\hline $\begin{array}{l}\text { RONZANI, T. M.; RODRIGUES, M. C. O Psicólogo ta Atençäo Primária à } \\
\text { Saúde: Contribuiçōes, Desa fios e Redirecionamentos. Psicologia: Ciência e } \\
\text { Profissäo, v. } 26, \text { n. } 1 \text {, p. } 132-143,2006 \text {. }\end{array}$ & 19 \\
\hline $\begin{array}{l}\text { MINTO, E. C. et al. Ensino de Habilidades de Vida na Escola: uma } \\
\text { Experiência com Adolescentes. Psicologia em Estudo, Maringá, v. } / 1 \text {, n. } 3 \text {, } \\
\text { p. } 561-568 \text {, set./dez. } 2006 \text {. }\end{array}$ & 22 \\
\hline $\begin{array}{l}\text { RAMOS, P. F.; PIO, D. A. M. Construção de um Projeto de Cuidado em } \\
\text { Saúde Mental ra Atençäo Básica. Psicologia: Ciência e Profissäo, v. } 30, \mathrm{n} \text {. } \\
\text { 1, p. } 212-223,2010 \text {. }\end{array}$ & 25 \\
\hline $\begin{array}{l}\text { ALMEIDA, M. M. et al. Contendo angústias familiares: Mediações } \\
\text { metafóricas em intervençōes Diagnósticas grupais com crianças e pais. } \\
\text { Jomal de Psicomálise, São Paulo, v. } 40, \text { n. } 72 \text {, p. } 113-133 \text {, jun. } 2007 \text {. }\end{array}$ & 26 \\
\hline $\begin{array}{l}\text { PAIVA, F. S; RODRIGUES, M. C. Habilidades de Vida: uma estratégia } \\
\text { preventiva ao consumo de substâncias psicoativas no cont exto educativo. } \\
\text { Estudos e Pesquisa em Psicologia, UERJ, v. } 8, \text { n. } 3 \text {, p. } 672-684,2^{\circ} \text { Semestre, } \\
2008 \text {. }\end{array}$ & 27 \\
\hline $\begin{array}{l}\text { BARRE TO, R. A. Psicanálise e arte: o programa de humanização no } \\
\text { hospital Säo Lucas em Sergipe. Estudos de Psicomálise, Aracaju, n 33, p. } \\
137-146 \text {, jul. } 2010 \text {. }\end{array}$ & 28 \\
\hline $\begin{array}{l}\text { SANTOS, M. A. Intervenção em saúde do trabalhador com profissionais do } \\
\text { sexo. Cadernos de Psicologia Social do Trabalho, v. } / 1, \mathrm{n} .1, \mathrm{p} .101-110 \text {, } \\
2008 \text {. }\end{array}$ & 29 \\
\hline $\begin{array}{l}\text { BORGES, E. P.; } \\
\text { Beneficios das at } \\
\text { Boletim Academid }\end{array}$ & 30 \\
\hline
\end{tabular}

Boletim Academia Poulista de Psicologia, v. 28, n. 02, p. 211-22, 2008.

É preciso ainda apontar que, nesse estudo, não se considerou um suposto progresso do conhecimento da Psicologia em relação à promoção de saúde, mas "as práticas discursivas que podiam constituir matrizes de conhecimentos possíveis" (FOUCAULT, 2010b, p. 5), regimes de verdade que conformam a promoção de saúde como um domínio de verdades no campo psicológico. Essa perspectiva apresenta-se na medida em que, nos artigos analisados, a promoção de saúde se constitui como uma autoevidência das ações que se estabelecem no interior da rede de saúde pública. A evidência da promoção de saúde no sentido de tornar-se uma matriz que borra os contornos que a constituem aparece na medida em que o conceito se torna autoexplicativo.

A autoevidência e a autoexplicação conformamse nos modos como essa ferramenta organiza as ações em saúde: enfoque no comportamento de risco; nível psicoterapêutico, psicopedagógico e psicoprofilático; conscientização; autonomia e cidadania; resiliencia psicológica, partir das mazelas íntimas desse sujeito para depois lançá-lo ao campo político; potencializar espaços de escuta e expressão, desenvolver uma leitura crítica diante das determinações sociais e culturais, reconhecer habilidades, saberes e competências; demanda espontânea, autoanálise, auto-organização, coletivos inteligentes; espaço terapêutico; melhoria na qualidade de vida da população em vários aspectos (TEXTO 06, $10,11,13,14,16,17,19)$.

A matriz do conhecimento reside não na unidade dessas definições, mas no modo como um regime de verdade as articula. Não se trata de um processo centrípeto, mas centrífugo, que encontra nessa pulverização da promoção de saúde algumas linhas de articulação possíveis para as práticas psicológicas, ou seja, todas essas distintas práticas produzem a promoção de saúde. Tais linhas aparecem quando o psicológico se torna uma forma de aclimatar a promoção de saúde, quando é o psicológico que torna possível o domínio de ações das práticas psicológicas. Nesse caso, tomar a Política como uma diretriz das práticas psicológicas em saúde torna necessária a inscrição de um domínio disciplinar no interior das práticas de promoção. É a necessidade de encontrar na abertura do campo psicológico aquilo que o salvaguardará: a interioridade do sujeito.

Essa interioridade passa a ser amalgamada com um plano de exterioridade que a própria Política produz como necessidades sociais: determinações sociais e culturais, demanda espontânea, melhoria na qualidade de vida da população em vários aspectos, cidadania, coletivos inteligentes. O psicológico toma espessura em relação a risco, autonomia, resiliência, limitações, sobrecarga, necessidades, desejos, habilidades, competências, potencialidades (TEXTO 07, 08, 11, 13, 15, 16, 19, 25).

Essa espessura do psicológico atualiza-se pelas ferramentas teóricas que o conformam: Cognitivocomportamental, Psicologia Social (materialismohistórico e construcionista/institucionalista) e Psicanálise. As ferramentas teóricas para dar forma ao psicológico e responder às necessidades sociais articulam-se com algumas políticas públicas e programas: $\underline{\text { Serviços }}$ substitutivos, CAPS, Reforma Psiquiátrica; PSF - ACS, PSF/PAIF (Assistência social - SUAS); Constituição, art. 196. Lei 8080/90; Lei 8142/90; NOB: 91, 93, 96; CIB, CIT PAB, FAE, ICCN, VISA, AFB; NOAS2011; SILOS; PAISC; Decreto 94.657; ECA; RS-Emprego (1994-1998) e Qualificar RS (1999- 2002); (PP Regional-Recursos FAT); Lei 10.216/2001; Resolução 196/96-CNS (TEXTO $01,02,06,13,15,16,17,18,25,26,27,28,29,30)$. 
A articulação do psicológico com necessidades sociais, nessa perspectiva de análise, passa a ser considerada como uma curva que estabelece relações "com as regras do campo em que se distribuem e se reproduzem" (DELEUZE, 2005, p. 15). As regras do campo são os regimes de verdade tecidos tanto pelas práticas psicológicas, como pelas políticas públicas. Esse encontro tem um efeito de raridade, já que, para o psicológico conservar-se em seu espaço, se torna necessário avizinhar-se de outras regras de existência, pulverizando o próprio regime de verdade que objetiva o fato psicológico.

A pulverização encontra-se quando as políticas públicas com as quais as práticas psicológicas dialogam não se referenciam na Política Nacional de Promoção de Saúde (BRASIL, 2006), mas naquelas que se apresentam como necessidades nos espaços de ação/intervenção das próprias práticas. Isso engendra espaços colaterais, adjacentes, que não encaminham para um axioma da Promoção de Saúde, mas para um conjunto heterogêneo de ações de promoção de saúde com protocolos de experiência: psicoterapêutico, psicopedagógico e psicoprofilático; participação ativa; capacidade de retornar às condições adaptativas anteriores, manutenção dos aspectos saudáveis, reconstrução de aprendizagens inadequadas; reconhecer habilidades, saberes e competências; autoanálise e auto-organização; trocar experiências e desenvolver suas potencialidades. (TEXTO 10, 08, 13, 16, 17). As ações de promoção de saúde encontram, na junção do terapêutico com as habilidades, as possibilidades de expressão dos protocolos de experiência. Esses protocolos indicam os caminhos que devem ser seguidos para se ascender a níveis maiores de saúde. Os protocolos organizam os modos de adaptação, manutenção, reconstrução, reconhecimentos, autoanálise e organização.

É forjada a existência de um domínio do sujeito psicológico a partir do terapêutico/comportamental - "no campo psicológico, as técnicas de mobilização forjadas não circulam de forma livre em sua extensão; elas trafegam apenas no campo de uma determinada orientação onde elas puderam ser forjadas" (FERREIRA, 2010, p. 55). É importante, por outro lado, marcar que essas ações e protocolos, são relações de força que atualizam os regimes de verdade no cotidiano, produzindo políticas de subjetivação, marcadas intensamente pelas noções de testemunho e de aprendizagem, as quais são discutidas a seguir.

\section{Políticas De Subjetivação: Testemunho E Aprendizagem}

Por políticas de subjetivação, compreendem-se formas de experiência produzidas por relações entre regimes de verdade, normativas de comportamento e tipos de subjetividade possíveis. Esses três eixos verdade, poder e subjetividade - constituem políticas de subjetivação (FOUCAULT, 2010b).

Os regimes de verdade que engendram modos de aclimatar a promoção de saúde nas práticas psicológicas tornam-se possíveis pelas relações de força que os envergam, que os atualizam. A atualização dos regimes de verdade apresenta-se nesta análise pelas ações cotidianas que colocam a promoção de saúde para funcionar. Essas ações dizem respeito ao conjunto de procedimentos e estratégias que se conformam como ações em promoção de saúde, ou seja, às práticas psicológicas que fabricam a promoção de saúde.

Os procedimentos organizam-se nas distintas formas de grupalismo: oficinas, grupos terapêuticos/ psicoterapêuticos, grupos operativos, grupos de apoio, grupos informativos, grupos de educação em saúde e psicoeducativos, treinamentos, palestras, capacitações (TEXTO 06, 07, 10, 11, 13, 17). Essas práticas grupais são dispositivos de constituição de sujeitos que garantem espaços não apenas de confiabilidade e apoio entre distintos sujeitos, mas de modalidades de apresentação de si. A apresentação de si é possível pelas distintas formas de testemunho provocadas pelos dispositivos. Esses dispositivos têm como procedimento o fazer falar. Conformam-se como modalidades de confissão coletivas. O objetivo da confissão aqui não é a salvação da alma (FOUCAULT, 1999), e sim a ascensão a níveis melhores de saúde. Nesse caso, o foco dos procedimentos não reside na confissão de segredos, intimidades, mas na apresentação dos comportamentos cotidianos e das condições de vida nas quais esses comportamentos são engendrados: desenvolver habilidades sociais, explicitar os próprios comportamentos e apoio ao outro; espaço de vínculos afetivos para suportes sociais, mudanças de comportamento; elevar autoestima, autoconfiança e aliviar sintomas (TEXTO 06, 10).

O testemunho é uma modalidade de relação consigo e não propriamente com a experiência da verdade no que tange às formas jurídicas. Como modalidade de relação consigo, o testemunho inscreve certa forma de experiência do sujeito em relação ao vivido (FOUCAULT, 2009). O vivido, pelo testemunho, é relatado, descrito, apresentado: gravidez, uso de álcool e drogas, comportamento sexual, violência doméstica (TEXTO 06, 07, 19). Como a Política de promoção à saúde avizinha as práticas psicológicas e aquilo que se coloca como necessidades sociais, o relato do testemunho conforma uma zona de interioridade a partir da exterioridade, ou seja, não é uma intimidade descolada das condições sociais nas quais se encontra. Pode-se dizer que a política alarga a intimidade, não mais restrita a um "eu envelopado pela pele" (ROSE, 2001), mas um eu como zona intermediária entre um mundo externo e um mundo interno. Os comportamentos, dessa forma, tornam-se a expressão desse processo de mediação do eu. O testemunho é compreendido, então, como uma via privilegiada para se acessar essa forma de negociação. A negociação, a partir da prática do testemunho, permitirá aos sujeitos modificarem comportamentos, melhorarem autoestima e autoconfiança, adquirirem habilidades sociais (TEXTO 06, 10). Essas novas formas de expressão de si tornam possíveis a evitação do agravamento de fatores emocionais que comprometem o espaço psicológico; arriscar-se para crescer; corrigir pensamentos; solucionar problemas (TEXTO 06, 13). 
O testemunho também agencia a noção de periculosidade em relação ao risco e à vulnerabilidade, e não propriamente a um mundo interno exclusivamente. A periculosidade constituirá uma das formas de enunciação do testemunho, na medida em que é ela que deve apresentar-se no testemunho. A periculosidade, nessas práticas psicológicas de promoção de saúde, não reside nos riscos psicopatológicos, mas nos comportamentos/ hábitos não-saudáveis e em sua relação com as condições de vida, pois promover saúde é trabalhar com os indivíduos diante de suas relações sociais (TEXTO 08). A relação com as condições de vida, a partir do dispositivo do testemunho, produz subjetividades mediante exercícios sobre repertórios que versem sobre temáticas cotidianas como a violência e que a partir disso desconstruiriam modelos universalizantes de sentidos que naturalizam certas verdades (TEXTO 07). O testemunho, nesse caso, permite uma liberdade em relação à periculosidade dos valores universalistas que naturalizam os riscos sociais. $\mathrm{O}$ testemunho grupal organiza os distintos repertórios para que estes sejam traduções do vivido, mas não do natural.

A periculosidade reside em uma relação de possibilidades comportamentais, ao passo que também opera como sua justificativa. A Política aponta a necessidade de se "cuidar da vida de modo que se reduzisse a vulnerabilidade ao adoecer e as chances de que ele seja produtor de incapacidade, de sofrimento crônico e de morte prematura de indivíduos e população" (BRASIL, 2006, p. 6). Estar sujeito a um campo de periculosidade, como aponta Foucault (2009, p. 85), não diz respeito a estar ou não em conformidade com a lei, mas às condições que "podem fazer, do que são capazes de fazer, do que estão sujeitos a fazer, do que estão na iminência de fazer".

Porém, o testemunho só tem eficácia como promoção de saúde na medida em que se trata de uma prática grupal. ${ }^{1}$ Para ter efeito, é necessário que o testemunho se dê em espaços coletivos. O coletivo, nessa tecnologia, refere-se ao trabalho com um conjunto reunido de indivíduos, caracterizado como apoio, suporte e rede. O grupalismo é fabricado por diferentes regimes de justificativa: produção de novos conhecimentos, práticas de diálogo, espaços de troca; compor redes sociais; melhorar condições de vida e cidadania (TEXTO 03, 04, 07). A Política é aclimatada pelas junções do indivíduo com o grupo, e essa junção produz outra, ou seja, a das necessidades sociais. O testemunho nos grupos da promoção de saúde permite que as práticas psicológicas acedam à articulação entre psiquismo e condições sociais. As práticas grupais permitem que o fato psicológico seja recomposto em outra trama de articulação. Em termos ontológicos, as práticas psicológicas de promoção de saúde, além de produzirem o sujeito-grupo a partir de linhas de periculosidade e condições sociais, também encontram no dispositivo aprendizagem/conhecimento outra linha de composição de políticas de subjetivação. Quer dizer, o testemunho grupal terá como correlato

\footnotetext{
${ }^{1}$ Os dispositivos grupais não são uma inovação contemporânea das práticas psicológicas, mas o que se quer apontar neste estudo é o modo como migram para a rede de atenção básica, constituindo-se como estratégia privilegiada dessas práticas.
}

a aprendizagem/conhecimento. Portanto, as práticas psicoeducativas passam a ser necessárias, o trabalho em grupo deve evoluir do conhecimento pessoal para a interação com o outro (TEXTO 22). É preciso aprender a lidar com essas fronteiras entre o externo e o interno, reconhecer habilidades, saberes e competências, ou seja, instaurar ações que contribuam para o autoconhecimento (TEXTO 16). As práticas grupais permitem uma relação estratégica que define o efeito do conhecimento em que o sujeito se encontra situado - "o caráter perspectivo do conhecimento não deriva da natureza humana, mas sempre do caráter polêmico e estratégico do conhecimento" (FOUCAULT, 2009, p. 25): correção de pensamentos, aprender a manifestar sentimentos e pensamentos, autoconhecimento e autorrevelação (TEXTO 06).

As práticas de autoconhecimento, ou de uma hermenêutica de si, são tributárias de tecnologias produzidas tanto pelo cristianismo quanto pela ciência moderna. Isso por si só não seria uma inovação das práticas psicológicas. O que se inventa com a aclimatação da promoção de saúde é situar o exercício do conhecimento como estratégia de saúde que avizinha o sujeito psicológico do sujeito social: exercitando não só o conhecimento técnico para abordar problemas de saúde/doença, mas, sobretudo valorizando a sua prática como sujeito e ator social, aprendendo a construir vínculos solidários (TEXTO 17). O autogoverno pelo conhecimento de si é necessário para o governo não do outro, mas da relação com o outro, das dificuldades de ser empático (TEXTO 22). Essas práticas de autoconhecimento não se impõem do exterior ao sujeito, mas são elas próprias constitutivas desse sujeito.

A fabricação de um sujeito do conhecimento e da relação com o coletivo abre-se com a própria Política, na medida em que "o paradigma promocional vem colocar a necessidade de que o processo de produção do conhecimento e das práticas no campo da saúde e, mais ainda, no campo das políticas públicas faça-se por meio da construção e da gestão compartilhadas" (BRASIL, 2006, p. 9). As práticas psicológicas, ao se depararem com esse arranjo da Política, acabam por ter que forjar tecnologias que se adaptem ao "novo paradigma". O caminho que se encontra é justamente em uma estratégia que permita enlaçar o sujeito psicológico com necessidades sociais, o sujeito psicológico com o coletivo. O autoconhecimento e a aprendizagem tornam-se um dispositivo que permite essa articulação, bem como a inscrição das práticas psicológicas no campo das políticas públicas, ou seja, a conformação das práticas psicológicas em um campo que lhes escapava.

\section{Breves considerações}

A aclimatação da promoção de saúde pelas práticas psicológicas se dá a partir de um exercício de controle e vigilância das condutas. A Política abre, para as práticas psicológicas, outro campo de investimentos, sobretudo, um campo de novas necessidades. De acordo com Ferreira (2010, p. 55), as práticas psicológicas constituem-se por “imóveis mutáveis”, persistindo a condição de manutenção 
de certas políticas de subjetivação. Essa manutenção reside nos procedimentos de aclimatação da diferença, ou seja, como capturar essas novas necessidades.

Nesse caso, o sujeito-comunidade potencial que se fabrica pela promoção de saúde é capturado e tornado um sujeito-grupo. As práticas grupais são um domínio das práticas psicológicas, um campo onde o sujeito psicológico se dá a conhecer na relação com um coletivo. Entretanto, o coletivo desse imóvel das práticas psicológicas constitui-se pelo conjunto de indivíduos arregimentados nos grupos. O coletivo perde o caráter de distintos vetores de subjetivação quando o que o organiza são políticas identitárias, ou seja, aquilo que os torna semelhantes em termos de regimes de visibilidade e dizibilidade. As necessidades sociais são transformadas em habilidades sociais que tornam possível um controle e vigilância não do mundo interno, mas das formas de relação entre os indivíduos nos grupos.

As necessidades sociais tornam-se o mutável nas práticas psicológicas. Mutável porque lhes permite salvaguardarem o psicológico, mas expandindo-o para as proposições da Política, expandindo o sujeito psicológico: agora não é o mundo interno exclusivamente que se torna o objeto das práticas psicológicas, e sim as habilidades para viver em um mundo externo. Além disso, as necessidades sociais tornam possível aclimatar o testemunho como uma forma de apresentação de si no coletivo, e não apenas nos espaços de confinamento psicológico. O testemunho torna possível transformar necessidades sociais em habilidades sociais a partir da fabricação do sujeito do conhecimento.

\section{Referências}

BRASIL. Ministério da Saúde. Portaria $n^{\circ}$ 687, de 30 de março de 2006. Aprova a Política de Promoção da Saúde. Disponível em: <http://189.28.128.100/dab/docs/legislacao/ portaria687_30_03_06.pdf>. Acesso em: 1 set. 2009.

BUSS, P. Uma introdução ao conceito de Promoção de saúde. In: CZERESNIA, D.; FREITAS, C. M. (Org.). Promoção de saúde: conceitos, reflexões, tendências. Rio de Janeiro: Fiocruz, 2003. p. 15-38.

CANADÁ. Carta de Otawa. Primeira Conferência Internacional sobre Promoção da Saúde, novembro de 1986.

DELEUZE, G. Foucault. Lisboa: Edições 70, 2005.

DELEUZE, G. Crítica e Clínica. Rio de Janeiro: Editora 34, 2008.

FERREIRA, A. A. L. O campo psicológico e seus múltiplos sistemas circulatórios. In FERREIRA, A. A. L. et al. (Org.). Teoria ator-rede e Psicologia. Rio de Janeiro: Nau, 2010. p. 44-59.

FERREIRA NETO, J. L. et al. Apontamentos sobre Promoção de Saúde e Biopoder. Saúde e Sociedade, São Paulo, v. 18, n. 3, p. 456-466, 2009.

FOUCAULT, M. História da sexualidade. Rio de Janeiro: Graal, 1999. v. 1.
FOUCAULT, M. Mesa-redonda em 20 de maio de 1978. In MOTTA, M. B. da. (Org.). Michel Foucault: estratégia, podersaber. Rio de Janeiro: Forense Universitária, 2003. Coleção Ditos \& Escritos, v. 4, p. 335-351.

FOUCAULT, M. A verdade e as formas jurídicas. Rio de Janeiro: Nau, 2009.

FOUCAULT, M. Do governo dos vivos. Curso no Collège de France, 1979-1980 (excertos). Tradução de Nildo Avelino. Rio de Janeiro: Achiamé, 2010a.

FOUCAULT, M. O governo de si e dos outros. São Paulo: Martins Fontes, 2010b.

ROSE, N. Como se deve fazer a história do eu? Educação \& Realidade, Porto Alegre, v. 26, n. 1, p. 33-57, jan./jun. 2001.

URSS. Declaração de Alma-Ata. Conferência Internacional sobre Cuidados de Saúde Primários. 12 de Setembro de 1978. Disponível em: <http://www.saudepublica.web.pt/05promocaosaude/Dec_Alma-Ata.htm>.Acesso em: 1 set. 2009.

Recebido em: 5 de novembro de 2012 Aceito em: 15 de abril de 2015 